\title{
Strategies to Effectively Dock Professional Music Performance Skills Teaching and Stage Practice
}

\author{
Yan Yan* \\ School of Music, Chengdu Normal University, Chengdu 611130, Sichuan Province, China \\ *Corresponding author: Yan Yan, 554933579@qq.com
}

\begin{abstract}
Music performance major requires students to have rich experience in professional stage practice. Therefore, in the process of promoting the teaching of music performance, the effective connection between the teaching of professional music performance skills and professional stage experience practice needs to be emphasized. With professional experience in teaching practice, this article analyzes the course teaching and stage practice of music performance, suggesting several problems in the current teaching methods, and from different angles, this article suggests countermeasures to effectively dock professional skills teaching with stage practice in hope to provide practical reference for relevant professionals so as to better cultivate and improve students' comprehensive application ability in music performance.
\end{abstract}

Keywords: Music performance major; Skills teaching; Stage practice; Effective docking strategy

Publication date: November 2021; Online publication: November 30, 2021

\section{Introduction}

In the teaching of music performance in colleges and universities, many teachers assume theoretical knowledge as the key learning content but neglect the cultivation of students' theoretical and practical operation ability. As a result, many students often have poor psychological quality and make errors during stage performance. In order to effectively solve such issues, teachers and schools should actively promote the teaching reform and innovation of docking professional skills teaching with stage practice, build a good learning environment, improve the rationality and perfection of the course system design, and promote the development of students' comprehensive ability in various aspects, so as to achieve the fundamental purpose of strengthening the skill training of music performers.

\section{Necessity of docking professional skills teaching with stage practice}

In the cultivation of artistic talents in music performance, the goal of colleges and universities is mainly to continuously improve students' professional comprehensive application skills and performance quality, including professional theoretical knowledge, practical operation skills, and professional stage practice experience. Therefore, schools need to actively promote the docking between professional basic skills teaching and professional stage experience practice.

\subsection{Practical needs of teaching reform}

Under the background of the curriculum reform in the new era, teachers and schools should fully respect the importance of cultivating students while teaching and strengthen its importance through various ways of teaching reform. 


\subsection{Inevitable requirement of social development}

Under the background of rapid economic and social development, people have put forward higher artistic requirements for the training of music performance personnel in schools. In order to fully meet the diverse needs of the audience from all aspects - visual, auditory, and spiritual, it is necessary to fully realize the effective coordination of professional music skills and stage practice to provide a comprehensive training for the improvement of students' stage ability and the strengthening of the artistic effect in stage performance.

\section{Analysis on the issues in docking professional skills teaching with stage practice}

\subsection{Lacking psychological quality}

In regard to stage performance, many students are directly affected by the stage effect because of their poor psychological quality. To be specific, these students are usually introverted, they lack stage confidence, and they prefer not to be in the spotlight. During performance, they are prone to experience stiff limbs, dull looks, and unnatural expressions. As a result, they are unable to accurately express the main content of the music, neither can they express the emotional aspect of the work well on stage. Colleges and universities should actively promote the improvement of students' emotional regulation skills throughout the course for those majoring in music performance ${ }^{[1]}$. This would solve the problem of the poor psychological quality of middle school students, which is obviously insufficient for stage performance in colleges and universities.

\subsection{Issues with memorizing scores}

In the process of cultivating and teaching artistic talents in music performance, college students are required to deeply and comprehensively remember the contents of certain music scores, so as to lay a solid foundation for future stage performance. Taking memory as the premise of learning, students should not only be confident in stage performance, but also improve their fluency and rhythm coherence, so as to fully demonstrate the true feeling and artistic thought of their practical works on stage and realize the internal emotional communication with the audience. However, in the teaching of music performance in colleges and universities, many college students often choose to memorize music scores by rote; however, this method does not benefit much. At the same time, stage performance is often affected by psychological factors, which may lead to a sudden blank and a bad stage performance experience.

\subsection{Lacking opportunities for stage practice}

In order to nurture excellent talents in music, the cultivation of a comprehensive ability in stage performance should be regarded as the primary training goal. This would help cultivate more excellent professional music performers. However, in the teaching of music performance in many schools, teachers do not provide enough opportunities for students to practice or learn on stage; thus, these students are not able to accumulate sufficient stage experience. As a result, it would be difficult to effectively improve their ability in stage performance, thus reducing their participation in music performance. If a student does not have enough experience in stage performance, he or she will not be able to accurately analyze or judge the environment in a live music performance on stage, and when they are required to perform on stage, they may feel extremely nervous ${ }^{[2]}$. It is far from enough for teachers to only carry out skill-based training in classrooms. Schools should actively innovate the teaching methods of professional talent training, actively provide students with more practical opportunities to participate in stage performance and strengthen the practical effect of professional talent training. 


\section{Implementation measures to effectively dock professional skills teaching with stage practice}

\subsection{Improving students' psychological quality}

\subsubsection{Teachers' encouragement}

Psychological quality is the most important factor to build confidence. Therefore, in the teaching of music performance, teachers should give full play to their guiding role, provide psychological support and encouragement to each student in a timely manner, strengthen the interpersonal relationship with students, as well as help each student to establish adequate confidence. For example, in a case where a student needs to practice for a stage performance, the teacher can provide encouragement through physical expression or language expression according to the performance of the student. By guiding each student to recognize his or her own psychological advantages in a timely manner, it would then be possible for each student to establish self-confidence as soon as possible.

\subsubsection{Scientific evaluation}

At present, the teaching of music performance often uses examination to evaluate students, which has a certain one-sidedness. It does not evaluate the students' situation well, and it also has certain limitations to the improvement of students' learning. Therefore, teachers should innovate the evaluation methods, establish a file for each student, and evaluate according to the improvement of each student, which is conducive to their individual strengths, thus encouraging students to build their self-confidence. Moreover, targeted improvement schemes can be formulated for students at different stages, so as to improve their learning efficiency and realize the connection between skills teaching and stage practice.

\subsection{Strengthening students' memory capacity}

\subsubsection{Innovating teaching methods}

In professional skills teaching of music performance in the past, teachers would often explain the basic contents, such as the theoretical knowledge of performance and performance skills to the students independently, and then they would encourage the students to practice independently. In order to effectively promote the docking of music teaching and professional music skills training in stage performance, first of all, teachers should timely and boldly innovate the traditional teaching method in schools; that is, all kinds of classroom teaching activities are bridged in such a way to combine all of these music activities into a miniature concert on stage. Through these lessons, the relationship between teachers and students in terms of "teaching" and "being taught" is completely broken and removed; thus, the theoretical knowledge points of stage art can be discussed and exchanged based on an equal learning spirit. In this way, teachers and students would collaborate with each other to achieve the goal of conducting a real "stage performance" [3]. Through such a method, it does not only effectively create a good learning environment in music classrooms, but also help the schools to truly achieve the goal for students to memorize and arrange music scores.

\subsubsection{Creating a good classroom environment}

In the teaching of music performance, it is important to maximize students' understanding, memory, and practical application in regard to music scores, create a good classroom environment for the students, fully mobilize their learning enthusiasm, as well as encourage them to actively participate in the understanding and memorizing of music scores. For example, in teaching songs, teachers should use the multimedia to display relevant contents, pictures, and play music videos, which are related to stage performance. The indepth teaching through this method can greatly expand students' understanding and their memory of the scores. At the same time, it can also fully exercise students' skills in music arrangement. 


\subsection{Providing opportunities for stage performance}

For music performance major in colleges and universities, in order to achieve the goal of bridging professional music skills with performance-based activities, it is necessary to provide more opportunities for students to perform on stage. With regard to this, colleges and universities should make every effort to cooperate with local radio and television stations on a regular basis. If students are required to perform on stage, colleges and universities should also regularly organize activities as such for students to actively participate in. Through such activities, students would gain opportunities to participate in performancebased activities, which is conducive to students as they continuously accumulate stage experience. In addition, colleges and universities can also arrange or organize various kinds of artistic performances by graduates on campus or even at nursing homes on a regular basis.

\section{Conclusion}

In the cultivation of artistic talents in music performance, it is very important to realize the connection between professional skills teaching and performance-based activities. However, there are still many issues that need to be solved. These issues must be properly dealt with in an appropriate way and in a timely manner. On the basis of all this, it is necessary to improve the psychological quality of the majority of students, strengthen their understanding and memory of music scores, provide more opportunities for performance-based activities, as well as exercise their and creative skills.

\section{Funding}

This study was supported by the Research on "Double Effect Teaching Practice" of Vocal Stage Art Practice Course (Number: 2021JG63).

\section{Disclosure statement}

The author declares that there is no conflict of interest.

\section{References}

[1] Shi S, 2019, Discussion on the Application of Flipped Classroom Teaching Mode in Music Performance Major of Colleges and Universities. Song of the Yellow River, (02): 100.

[2] Wu D, 2018, Discussion on Innovation of Music Performance Teaching with Emphasis on Students' Vocational Post Ability Training. Journal of Hunan Mass Media Vocational Technical College, 18(04): 113-116.

[3] Kang K, Xiao ZP, 2018, Research and Reflection on the Curriculum System of Music and Performance Major in High Vocational Colleges - Based on the Data of 13 Colleges and Universities. Musical Works, (07): 185-187. 